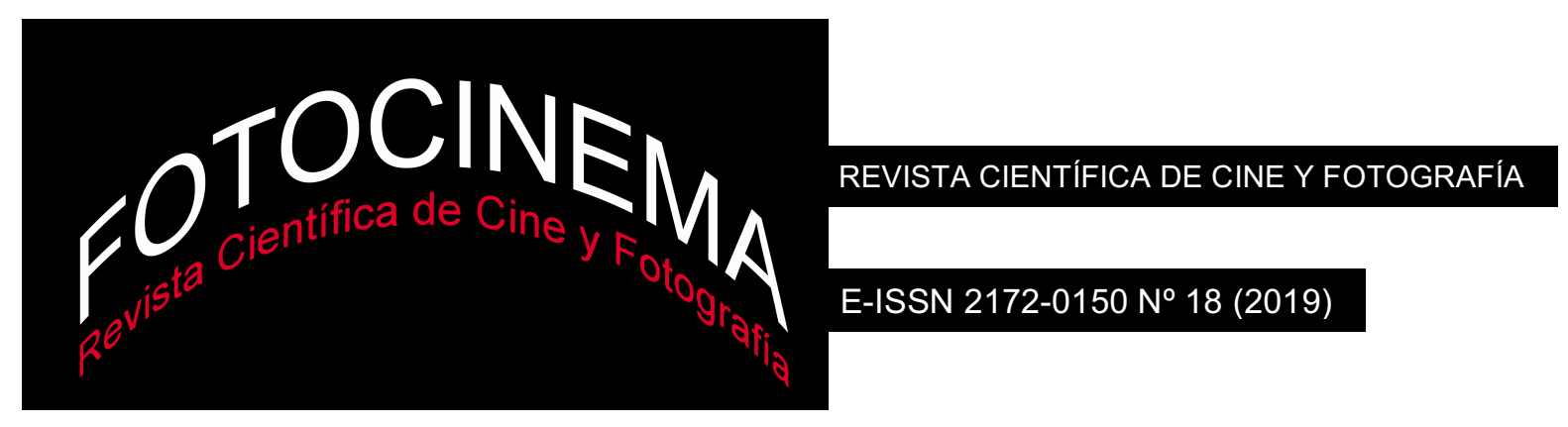

\title{
Palabra e imagen
}

\section{Word and Image}

Edoardo Balletta (Università di Bologna, Italia)

Manuel Blanco

(Universidad de Huelva, España)

El siglo XX fue el siglo de la imagen. Y ella ha sido -y sigue siendo- un motor de producción iconográfica global. Alguno de los hechos más significativos del pasado siglo fueron afectados (cuando no, directamente producidos) por la dimensión visual de un acontecimiento histórico. Baste pensar en el ejemplo que sigue: la liberación de la Europa del nazismo fue a manos del ejército rojo -sea por los planes estratégicos de contención, sea por las bajas del propio despliegue ruso, sea por la transmisión oral de los pueblos liberados- ello unido, si bien en menor medida, al concurso de los ejércitos aliados en la contienda: éstos últimos con un papel coadyuvante, casi subordinado al rol soviético en los frentes orientales. Ese rol secundario aliado era percibido por todos los estamentos de la sociedad europea. Y, tras más de medio siglo de producción iconográfica norteamericana (muy especialmente en el campo de la cinematografía de Hollywood), la responsabilidad de la derrota del nacismo no recae, a ojos de la opinión pública -como en los años coetáneos al propio acontecimiento- en el ejército ruso: las generaciones más jóvenes, como recientemente analizó un estudio $^{1}$, creen firmemente que el ejército americano derrotó él sólo al nacismo,

\footnotetext{
${ }^{1}$ Bajo la dirección de Jean Stoetzel, en una encuesta realizada por el IFOP en mayo de 1945 en todo el territorio francés (ya liberado), ante la pregunta: ¿qué nación considera que más ha contribuido a la derrota de Alemania?, los datos son los que siguen: el 57\% de los encuestados contestó que la URSS, sólo el 20\% consideraba que habían sido Estados Unidos (pese del desembarco de Normandía). En 1994, ya con Alemania reunificada, y con motivo del quincuagésimo aniversario del desembarco de Normandía -6 de junio de 1944- el IFOP realizó una encuesta internacional para Le Monde. Planteó de nuevo la misma cuestión: el $49 \%$ de los encuestados franceses citaban a Estados Unidos, el 25\% a la URSS y el 16\% a Reino Unido. En junio de 2004 el IFOP realiza una nueva encuesta, esta vez para el diario Le Figaro. Ante la misma pregunta, el 58\% contesta a favor de los Estados Unidos y sólo el 20\% a favor de la URSS.
} 
quizás con alguna ayuda europea. La imagen ha cambiado la historia, y no sólo: también la manera de contarla y cantarla. En el siglo XXI este poder se ha multiplicado exponencialmente, tejiendo una nueva relación entre la fotografía y la ciudadanía. Tamizando cada acto vital (un café, un paseo, una comida o una ducha) con su consecuente realización fotográfica del momento y su plasmación en los social media.

La palabra, por otro lado, fue el medio vehicular de transmisión del conocimiento de la humanidad -desde la práctica invención de la misma- hasta nuestros días. Si bien, ha ido sufriendo, como es fácil imaginárselo, diferentes avatares en su recorrido (que va desde la invención de la imprenta a las campañas bélicas imperiales que difundieron la palabra como medio de comunicación entre los pueblos). Con todo, el nuevo contexto del siglo XXI, emanado de la crisis de las puntocom y la proliferación de la tecnología móvil, ha supuesto una revisión del propio papel de la palabra como transmisor de ideas y conceptos.

No obstante, ambas esferas convergen en una nueva etapa comunicativa que, desde la irrupción de la era digital, está reescribiendo el viejo proyecto euroccidental que, como sociedad de la información, estamos reedificando en lo colectivo. Un nuevo sujeto político, social y creativo que más que inserto en una época de cambios nos lleva a ver nuestro momento histórico como un cambio de época: asistimos entre bostezos a un momento que algún día los libros narrarán como algo histórico.

La irrupción de una nueva cultura digital ha cambiado el orden establecido en casi todas las esferas sociales. La digitalización, como mero instrumento aplicable a todos los aspectos de la vida, ha favorecido en occidente (y no sólo) la proliferación de un tipo de relaciones humanas tamizadas de tecnología que, a la postre, han cristalizado en un nuevo tipo de amor digital, un consumo empresarial digital de los elementos, un tipo virtualizable de transacciones económicas y monetarias... La cultura digital, además, se vale de la palabra (escrita pero no sólo) como correa de transmisión junto a la propia construcción de imaginario digital- en el nuevo universo de los social.

Por ello, nos interesa indagar desde una perspectiva historiográfica cómo la palabra y la imagen han contribuido a los cambios sociales que, a lo largo del devenir de la 
historia, han tenido lugar en los viejos y nuevos órdenes mundiales. La palabra y la imagen (y la relación entre ambas) como motor de producción historiográfica aplicada. ¿Desde qué tradiciones teóricas reflexionar?, ¿qué prácticas desde el campo de la politología se han hecho, con la palabra e imagen como marco, para influir en el curso de los acontecimientos - sea a nivel popular como intelectual-? ¿El cine ha cambiado esencialmente con el nuevo paradigma digital multiplataforma?, ¿̇la palabra dentro del cine cómo evolucionó desde su uso primigenio a los últimos avances digitales? ¿Qué films son especialmente paradigmáticos de la relación palabra-imagen?

Begoña Sánchez Galán, de la Universidad de Valladolid, analiza el momento crítico en que el cine deja de ser un experimento científico excéntrico para pasar a ser hacia la mitad de dicho siglo XX el gran espectáculo de masas. Ello centrado en los títulos de crédito de las películas que, en los albores del cine tradicional, eran hechos a mano y postergados siempre a un rol marginal (a menudo tanto los bocetos como los diseños finales, una vez realizado el filme, se tiraban a la basura). Pero sus diseños, su tipografía, sus propuestas, eran la punta de lanza (abrían y cerraban la cinta) y, al observarlos, podemos conocer aspectos nada desdeñables como: época contextual, relación del artista dentro de la cadena de producción, creatividad, detalles de la técnica cinematográfica, etc. Sánchez Galán accedió y catalogó el fondo de la filmoteca y ha conseguido enlazar 184 películas a los 1028 materiales encontrados. Tras este artículo, presentado a la sociedad investigadora en Fotocinema y, siempre gracias al trabajo de esta autora, estos fondos de la filmoteca están digitalizados, inventariados y son consultables por primera vez. Y con ellos una serie de aspectos resultantes de la investigación, tales como el descubrimiento de producciones perdidas, el sacar a la luz las relaciones entre diferentes artistas participantes en la creatividad y, en definitiva, la investigación de procesos que se creían muy marginales dentro de la producción cinematográfica de la época y que, sin embargo, se nos descubren como capitales.

Sobre el lenguaje y sus derivados en la cinematografía, bien sea como subtítulos, intertítulos, traducciones y demás uso léxico ha investigado Fran Mateu, quien pone el foco en que la palabra nunca se respetó tanto en su lengua original como ahora, incluso en lenguas sintéticas (esto es: reconstruidas) como en el famoso lenguaje élfico de $E l$ señor de los anillos. Ejemplifica sus postulados en la película $E l$ 
nombre de la rosa, basada como es sabido en la novela del mismo nombre obra del padre de la semiótica Umberto Eco. En la novela, y también en el filme, buena parte de los detalles que posibilitan el discurrir del argumento se ofrece en la lengua vehicular de la época medieval: el latín. Así mismo, se acude a otras lenguas en momentos de tensión argumental, pues algunos de sus protagonistas son políglotas. Esto supone que, a la postre, en la versión original se puedan escuchar hasta siete lenguas. Pero, como señala Mateu, el doblaje al español conlleva que aumenten el número de escenas. Es, en cualquier caso, un debate interesante que nos lleva a pensar, desde la palabra y en torno a la palabra, el significado y el significante de su presencia en el cine.

La investigadora Jiménez Gómez, de la Universidad de Córdoba, aborda el asunto siempre tangencial de la relación entre lenguajes, en este caso la relación siempre conflictiva que se establece entre el tejido literario (en tanto textus, -us) y su traslación al lenguaje cinematográfico de la gran pantalla. En concreto se vale de Tormento del bilbaíno Pedro Olea que adaptó la obra homónima de Benito Pérez Galdós. Arranca con un documentado recorrido histórico que bucea entre la relación de ambos lenguajes. Además, es justo reseñar que este particular sigue siendo de máxima actualidad, basta recordar que casi la mitad de las películas que obtuvieron galardón en los últimos premios del Cine Europeo -celebrados en Sevilla en el mes de diciembre de 2018- estaban basadas en novelas. La propuesta, tras este marco referencial, se vale del trabajo de Olea para disertar sobre el universo galdosiano y las particularidades del medio cinematográfico. Máxime cuando este cineasta es, como bien se dice, una mente preclara que aportó mucho a la construcción de un nuevo paradigma cinematográfico: compuesto de revolucionarios movimientos de cámara para un diferente acercamiento a la cinética actoral-, un aporte diferenciado al montaje lineal y, en definitiva, un mecanismo diferente a la hora de componer un metraje jalonado de primeros planos y planos detalle para acompasar la palabra con una filosofía visual que la arrope. El artículo se detiene, con agudeza, en aspectos que normalmente $-\mathrm{y}$ por desgracia para la literatura científica cinematográfica- suelen quedar fuera del análisis, tales como la iluminación (a menudo achacada a "los eléctricos" como si su aporte no fuera capital a la hora de plasmar el trabajo del director de fotografía), o de los movimientos de cámara (como si ello no fuera ya de por sí fundamental en el discurso fílmico, y aún más -cabría decir- con la irrupción 
del tsunami digital). Ciertamente, también se examina la imbricación entre todas estas esferas descritas y el propio oficio actoral, entre otros particulares. Además, escoge algunas escenas que, a modo de ejemplo, muestran y demuestran su análisis ulterior. Pero, y esto es un aspecto diferencial de este trabajo, es capaz de poner en relación todo lo visto con las particularidades de la escritura: una suerte de teoría de la literatura que encuentra en esta película una vía para la adaptación, a saber: la relación entre metáforas y movimientos de cámara, código visual cinematográfico y léxico literario escrito, entre otros. Todo ello vale para, a ojos de la investigadora, poder afirmar la entrada de esta película en la categoría de reescritura para lenguaje cinematográfico de un texto literario: no como una mera adaptación sino, antes al contrario, como nuevo tejido y traducción entre lenguas, si bien con las particularidades idiomáticas que conllevan ambos lenguajes y que, un autor como Pedro Olea, supo llevar a una de sus cotas más altas en la cinematografía española.

A la Universidad Rey Juan Carlos pertenece Elena Rosillo que, en su artículo, investiga la relación entre palabra e imagen en 1, 2, 3 al escondite inglés del polifacético cineasta Iván Zulueta. Esta producción viene al calor de la reflexión que se está haciendo sobre imagen y palabra y, ciertamente, la película se rueda en un momento crucial de nuestra cinematografía. Producida y terminada en los estertores del franquismo es, en sí misma, un claro exponente en la cinematografía de lo que en esta época se convino en llamar la contracultura o underground. El underground ibérico, conviene recordarlo aunque no sea el objeto de estudio de este artículo, posee muchas particularidades que lo diferencian de sus coetáneos europeos. La primera es que se desarrolló en los estertores de un régimen, el franquista que, si bien fue aliado del nazifascismo de la Segunda Guerra Mundial, acabó sus días (en los finales 60) siendo una dictadura controlada por los poderes fácticos, más o menos en connivencia con los sistemas Europeos -con los que el régimen ya mantenía relaciones diplomáticas y negocios-, y muy en la órbita americana. En esos mismos años la contracultura europea - a menudo con un brazo armado- escribía con sangre la construcción de ese microclima alternativo a la socialdemocracia burguesa europeísta y la injerencia soviética -radio Alice en Bologna, el mayo de París, la primavera de Praga, entre otros²-.

\footnotetext{
2 Sobre este particular puede consultarse el número 17 del pasado año de esta misma revista, Fotocinema, titulada: Las revoluciones en el visor.
} 
Sobre si el underground ibérico puede o no insertarse en la contracultura de los años 70 en el Madrid de la época (que fue sin duda su epicentro), es muy esclarecedor este artículo pues sostiene que 1, 2, 3 al escondite inglés sí pertenece a dicho movimiento y lo justifica. Y lo hará, además, no solo atendiendo a un análisis fílmico sino, y esto es lo novedoso de la propuesta, contraponiendo un estudio cinematográfico secuencial y literario de algunos de sus diálogos. Cada análisis, además, se centra en una situación contextual histórica en que se desarrolló ese particular. Y pone, es justo reseñarlo, en relación las diferentes ramas de la contracultura: la música (desde los cantautores a lo moderno), lo literario (muy presente en los diálogos que tienen cierta vecindad con los textos situacionistas de la época) y, por supuesto, el propio cine. A menudo todas esas ramas están presentes en el metraje de la propuesta. Además, esta misma música -aunque no solo, probado queda-, hace las veces de hilo conductor, como bien indica Rosillo, no sólo del metraje de esta cinta si no, más allá aún, de las mismas ramas de un árbol común que sería la contracultura ibérica.

Juan Carlos Pueo analiza en su propuesta el bloqueo del escritor (crisis creativa asociada a la tabula rasa) en The lost weekend de Billy Wilder: una película y un director de la llamada época dorada de Hollywood. Con una lectura muy sugerente el autor nos propone una mirada a esa sociedad para argumentar que, en realidad, en el caso del protagonista, el asunto y trasunto de su personaje no es el miedo a la tabula rasa en sí, sino más bien a una homosexualidad que en el Hollywood de la época del código Hays, no era ni si quiera pensable insinuar. Para ello, el cine se valía de toda suerte de recursos metafóricos y metonímicos (obviamente heredados y traducidos de la propia literatura y adaptados al lenguaje fílmico), para sugerir universos vetados por la censura. El artículo nos permite hacer un recorrido por la relación siempre conflictiva entre el creador (el literato) y el alcohol. Máxime en unos años en que la presión de los grupos del cristianismo puritano norteamericano acababan de conseguir un establecimiento de la ley seca, ley harto combatida por una progresía creativa que vinculaba el alcohol a la desinhibición de normas morales conservadoras y vinculaba, además, la bebida como catalizador de la nueva sociedad libre europea, teniendo su topos en el añorado París nocturno de los años 20 de las vanguardias artísticas. El autor reflexiona sobre el lenguaje cinematográfico como manta telúrica que engloba aspectos sociales no menores -masculinidad, puritanismos sociales, establishment de Hollywwod- que se traducen y traslucen en el metraje de The lost 
weekend de forma paradigmática y que son, acaso como causa y efecto, un ejemplo perfecto de la relación entre palabra e imagen (cinematográfica) como mirilla para descubrir el mundo que era.

Los autores Emeterio Díez y Jorge Iván Sánchez, de la Universidad Camilo José Cela (España) y la Universidad del Atlántico (Colombia) respectivamente, se centran en el trabajo de mesa en el teatro (en tanto palabra escrita y obra literaria) y su relación con el cine, en concreto en un momento clave como es la lectura de guion. Examinan la relación del cine con el teatro, no desde la evolución histórica -que no la tiene-, sino desde la diferencia entre ambos lenguajes y las coincidencias (actores, escenografía, atrezzo, etc.). Conviene aquí recordar que el cine comienza a diferenciarse de la fotografía cuando de él hace el movimiento obrero un arma política, tanto que, en esos primeros compases, el cine es justamente lo opuesto al concepto fordista (al que aluden los autores) de producción industrial: el cine era una máquina de manivela humilde, una sábana, y una bicicleta: proyectando en las paredes de los sindicatos historias que, más que narrar, eran un arma política. Será, como decimos, bien entrado el siglo XX (básicamente no antes de mediados de los años 30) cuando el cine se convierta en un instrumento al servicio de la propaganda nazi (que crea por primera vez un "Festival de cine" y, como consecuencia, aparecen en su contra los festivales cinematográficos de Cannes, Moscú, etc.). Díez y Sánchez reflexionan inicialmente sobre esa técnica cinematográfica primigenia para estudiar cómo evoluciona hasta llegar a nuestros días. En ese recorrido histórico se analizan las lecturas de guiones (lecturas de mesa) de buena parte de las películas del cine español de más éxito reciente. Se abordan, además, aspectos no siempre bien entendidos por el mundo del cine como la necesidad de estos trabajadores de confeccionarse una suerte de otredad vital temporal para abordar el proceso de creación de un personaje: no por casualidad -como se alude en el artículo- el actor Luis Tosar se trasladó a vivir a una aldea varias semanas para construir el contexto vital de un personaje al que debía interpretar en la gran pantalla (Flores de otro mundo, de Bollaín) u otros ejemplos menos conocidos como el del actor Antonio de la Torre que acudió en varias ocasiones a un cuarto oscuro nocturno de Chueca para interpretar a un personaje homosexual en Los amantes pasajeros de Almodóvar. Se hace un recorrido -jalonado con numerosas piezas fotográficas, además- por títulos tales como El bar (Álex de la Iglesia, 2017), La casa de papel (Álex Pina, 2017) o La 
peste (Alberto Rodríguez, 2018). Además, se tratan aspectos como la digitalización de los procesos, anecdotario o pormenores sobre las particularidades de los oficios del cine que son, como se indica, en ocasiones coincidentes con los del teatro (palabra escrita y viva, a la vez).

Froiz Casal, de la Universidad de Santiago de Compostela, presenta un artículo donde tendremos ocasión de apreciar el uso del globo de texto como transposición del diálogo del cómic al cine en ¿quién quiere matar a Jessie? del director de cine checo de los 60 Vorlíček. La relación entre cómic y cine traza ya una trayectoria sólida, especialmente en los últimos años en que se cuentan por decenas los blockbusters de Hollywood que son adaptaciones, pero la novedad de esta propuesta consiste en centrarse en el cine del otro lado del telón de acero, en un momento, además, en que a Europa prácticamente no llegaba ninguna producción de fuera del marco euroccidental. Por ello produce asombro ver esos recursos narrativos de palabras insertas en imágenes de la película, creando un discurso bien alejado de las producciones americanas de la época.

Desde la Universidad de Navarra, Deborah Rodríguez investiga sobre las implicaciones filosóficas y metafísicas de Arrival (La llegada, en español) de Denis Villeneuve. Si bien su promoción se hizo como una producción de ciencia ficción, más bien podría pasar como una propuesta donde, lo fantástico, no es sino una excusa para llevar ese discurso -bien humano, por otro lado- a otro espectro. $\mathrm{Y}$ atina Rodríguez cuando señala que, en este filme, la lengua -como hacedor de palabras- y la imagen -y la imagen de estas palabras, a propósito- ocupan un lugar tangencial en la trama. Mi patria es mi lengua, cantaba el poeta, y mucho se habla de ello en este texto. A veces para cuestionar el lenguaje como único vehículo de comunicación entre las personas, otras para enriquecer esa vía lingüística con unas visiones conceptuales no exentas, sin embargo, al propio habla (aun cuando no sepamos codificar dicho habla). Se analiza de forma pormenorizada, por último, la metáfora como herramienta portadora de sentido y definición. Mención aparte merece la reflexión en el metraje sobre la noción de "tiempo" sobre la que se centra, cómo evitarlo, el artículo presente. La cinta fantasea con una noción de tiempo no lineal, al tiempo que juega a cómo nosotros seríamos capaces, o no, de asumirlo.

Sobre fotogramas y pantallas versa el artículo Verónica Tell que trata de esclarecer la relación de la materia física con palabra e imagen en el nuevo paradigma -sin 
materia, esto es, binario- de la cultura digital. Ciertamente el hecho fotográfico cambia en la medida en que varían los conceptos que lo habitan, y este texto arroja luz sobre los usos del hecho fotográfico en tanto gramática histórica de lo referenciado. Si el medio es el mensaje aquí se reflexiona sobre la conexión de palabra y tecnología en buena parte de los subproductos del nuevo modelo de producción de iconografía digital: los sms, los diseños digitales con software de render $3 \mathrm{D}$, etc. Se trata, si bien no siempre, de imágenes autoreferenciadas, metaimágenes, que subvierten el mensaje inicial y crean un discurso de alteridad.

Cierra el número Leticia Rigat de la Universidad de Buenos Aires que reflexiona sobre el cambio de paradigma en la fotografía que pasa, de la corporeidad del siglo XX a la digitalización en el XXI, del valor principal de recuerdo al de sujeto político de la actualidad y, en definitiva, de un fin en sí mismo a un mero camino para la obtención de otro fin. Si bien es un asunto analizado de manera profusa, no es menos cierto que Rigat atina a enfocar determinados aspectos que sí se nos antojan inéditos o, al menos, no lo suficientemente abordados, asuntos tales como la diferencia temporal entre la creación y la percepción en el caso de la analógica (días de trabajo para revelar, parar y fijar, así como secar y positivar) y la digital (inmediata en el visor del aparato). O el estudio de la fotografía en tanto artefacto cultural ergo, analizando el contexto que la circunda, es en sí mismo un elemento decodificador de nuestros días. Ello, además, a través de un recorrido por los principales movimientos y corrientes que han examinado la fotografía como comunicación visual estética: la semiótica, la historia del arte... y más aún las ciencias sociales en su conjunto.

La palabra y la imagen, a modo de eje transectorial articulan un nuevo sistema comunicativo y mediático. Y crean un nuevo horizonte cultural sin duda tamizado por las coordenadas que impone la digitalización. Por ello este número se convierte en foto fija de un momento de cambio, de ruptura. Una foto fija que cambiará con la obsolescencia que marca el fin precipitado de las cosas. Pero por ello doblemente válida. No solo en lo cinematográfico, sino también en lo literario y, por tanto, de lo que de la mezcolanza de ambos lenguajes surja. 